\title{
Pengembangan Media Pembelajaran Interaktif Berbasis Android Untuk Pembelajaran Terbuka dan Jarak Jauh di Universitas Pendidikan Indonesia
}

\author{
Feri Hidayatullah Firmansyah ${ }^{1}$, Intan Permata Sari², Musyarofah ${ }^{3}$ \\ 1,2) Program Studi Pendidikan Multimedia, Kampus UPI di Cibiru, \\ Universitas Pendidikan Indonesia \\ Jl. Raya Cibiru Km 15 Bandung 40393 \\ Email: 1feri.firmansyah@upi.edu, 2intanpermatasari@upi.edu \\ 3) SMAN 1 Kalitidu \\ Jl. Raya Ngasem No. 458 Kec. Kalitidu, Kab. Bojonegoro \\ Email: arofah6326@yahoo.com
}

\begin{abstract}
ABSTRAK
Penelitian ini bertujuan untuk mengembangkan sebuah media pembelajaran sebagai pilot project pengembangan pembelajaran terbuka dan jarak jauh. Media pembelajaran yang dikembangkan berupa aplikasi berbasis android dengan metode pembelajaran berbasis proyek. Media dibuat dengan menyesuaikan tujuan proses pembelajaran, oleh karena itu media harus memiliki acuan untuk mengembangkan konten materi yang akan dibahas di dalamnya. Konten meliputi RPS, modul pembelajaran dan kisi-kisi penilaian. Media pembelajaran yang dibuat berbasis google sehingga mendukung semua jenis perangkat untuk mengakses modul ini. Dengan metode Rapid Application Development (RAD) tahapan pengembangan modul dapat diselesaikan sesuai dengan waktu yang direncanakan. Di dalam modul yang dikembangkan terdapat tujuan pembelajaran, petunjuk kegiatan praktik, alat dan bahan, dasar teori, latihan dan tugas. Dalam materinya juga diberikan video contoh materi yang dipelajari. Penelitian saat ini telah sampai tahap pengisian angket oleh mahasiswa dan pengolahan data angket. Hasil penelitian menunjukkan respon positif dari mahasiswa dibuktikan dengan kurva normal dari penilaian yang telah dilaksanakan. Dari data yang diperoleh dapat digunakan sebagai rujukan dalam pengembangan media pembelajaran interaktif yang mudah untuk dikembangkan dalam pembelajaran.
\end{abstract}

Kata kunci: Media Pembelajaran Digital Interaktif, Media Pembelajaran Berbasis Android, Pembelajaran Terbuka dan Jarak Jauh, Pembelajaran 4.0

\begin{abstract}
This research aims to develop a learning media as a pilot project for the development of open and distance learning. Learning media developed in the form of android-based applications with project-based learning methods. Media is made by adjusting the objectives of the learning process, therefore the media must have a reference to develop the content of the material to be discussed in it. Content includes RPS, learning modules and assessment grids. Learning media created based on google so that it supports all types of devices to access this module. With the Rapid Application Development (RAD) method the module development stages can be completed in accordance with the planned time. In the module developed there are learning objectives, practical activities instructions, tools and materials, basic theories, exercises and assignments. The material is also given a video sample of the material being studied. The current research has reached the stage of questionnaire filling by students and questionnaire data processing. The results showed a positive response from students evidenced by the normal curve of the assessment that has been carried out. From the data obtained can be used as a reference in the development of interactive learning media that are easy to develop in learning.
\end{abstract}

Keywords: Interactive Digital Learning Media, Android Based Learning Media, Open and Distance Learning, Learning 4.0

\section{Pendahuluan}

Indonesia sekarang telah memasuki era perubahan revolusi industri 4.0 yang berimbas pada perubahan perilaku masyarakat baik itu secara sosial maupun budaya. Pengelolaan korporasi sekarang sudah mengarah kepada ketergantungan akan teknologi informasi dimana beberapa jenis pekerjaan yang dulunya dikerjakan 
oleh manusia telah diisi dengan oleh mesin. Selain di bidang korporasi era revolusi industri 4.0 juga berdampak pada keterampilan sumber daya manusia (SDM) dalam kecakapan pekerjaan. Bentuk kecakapan itu bukan hanya sesuai dengan bidang keahlian yang telah dipelajari selama belajar di pendidikan formal tetapi juga kecakapan dalam menggunakan teknologi dan informasi.

Salah satu aktifitas yang terdampak dari revolusi industri 4.0 adalah proses pembelajaran. Dimana dengan adanya revolusi industri 4.0 ini proses pembelajaran memiliki peran penting dalam memberikan kecakapan tambahan bagi peserta didik tentang kecakapan teknologi dan informasi. Data Kementerian Riset, Teknologi, dan Pendidikan Tinggi menyatakan bahwa Indonesia perlu meningkatkan kualitas keterampilan tenaga kerja dengan teknologi digital dan lebih dari 55\% organisasi menyatakan bahwa digital talent gap semakin melebar[1] yang artinya bahwa seiring perkembangan teknologi yang diterapkan di korporasi semakin maju tetapi tidak diimbangi dengan keterampilan SDM dalam mengelola teknologi.

Maka dari itu pemerintah menyatakan bahwa perlu adanya perkembangan model pembelajaran yang sesuai dengan perkembangan era revolusi industri 4.0 ini yakni pembelajaran 4.0 dimana model pembelajaran ini menekankan peserta didik agar mengembangkan studi literasi dengan dukungan teknologi. Selama ini diketahui bahwa literasi dalam pendidikan hanya terbatas pada proses membaca, menulis dan matematika sebagai modal dasar berkiprah di masyarakat. Di pembelajaran 4.0 ini diharapkan peserta didik mampu memahami jenis literasi baru yang dapat membuat mereka lebih kompetitif diantaranya berupa literasi data, literasi teknologi, dan literasi manusia.

Literasi Data adalah kemampuan untuk membaca, analisis, dan menggunakan informasi (berupa big data) di dunia digital. Dimana dengan dukungan teknologi saat ini proses pembelajaran tak hanya terpaku pada sebuah sumber belajar melainkan dapat dieksplorasi lebih mendalam secara online maupun media digital berbasis gadget. Literasi teknologi adalah pemahaman tentang cara kerja mesin aplikasi teknologi (dapat berupa coding, artificial intelligence, dan engineering principles). Sedangkan literasi manusia erat kaitannya dengan humanities, komunikasi, dan desain. Literasi manusia ini didapatkan peserta didik dalam kehidupan sosial baik di lingkungan akademik maupun masyarakat. Jika ketiga jenis literasi ini dapat dikemas dalam satu media pembelajaran maka diharapkan lulusan lebih kompetitif di masyarakat.

Dalam roadmap penelitian ini menjelaskan tentang rancangan model pembelajaran 4.0 yang dimulai dari aktivitas awal yakni pengembangan media pembelajaran interaktif berbasis android yang akan diimplementasikan dalam model pembelajaran terbuka dan jarak jauh. Objek penelitian adalah mahasiswa pendidikan multimedia Universitas Pendidikan Indonesia di Cibiru dimana konten atau materi yang akan dibahas adalah pengolahan citra digital. Dalam pengembangan pembelajaran 4.0 pemerintah juga menyandingkan model project base learning (PBL) dalam prosesnya. Hal ini bertujuan agar peserta didikdisini adalah mahasiswa-dapat menguasai ketiga jenis literasi baru baik secara langsung maupun tidak langsung.

Aplikasi yang dibuat berbasis android bertujuan agar memudahkan mahasiswa dalam pembelajaran dan agar dapat melakukan pembelajaran dimana saja. Dengan beberapa dukungan aplikasi lain media pembelajaran digunakan sebagai referensi dalam proses pembelajaran dan terdapat beberapa praktik berbasis proyek di setiap materinya. Dengan ICT mahasiswa dapat berinteraksi langsung via online meskipun pengajar-disini adalah dosen-tidak menyampaikan materi secara tatap muka.

Media pembelajaran diimplementasikan dalam proses pembelajaran yang dikemas dengan model pembelajaran terbuka yang tidak terikat waktu dan tempat dan secara jarak jauh (online). Pengembangan media ini merupakan penelitian awal dalam mengembangkan model pembelajaran 4.0.

\section{Metode Penelitian}

Pengembangan media pembelajaran erat kaitannya dengan kesesuain model dan metode dalam proses pembelajaran. Proses pembelajaran yang baik adalah perencanaan yang baik dan media yang sesuai dengan tema pembelajaran. Oleh karena itu agar media pembelajaran yang dikembangkan sesuai dengan topik pembelajaran yakni pengelolaan citra digital maka media yang dikembangkan harus sesuai dengan tujuan pembelajaran. Dalam penelitian ini terdapat dua metode yang digunakan yakni Design and Development (DnD) dan Rapid Application Development (RAD).

$\mathrm{DnD}$ digunakan untuk menentukan kesesuaian media terhadap perangkat pembelajaran. Berikut sistematika metode $\mathrm{DnD}$ dalam penelitian ini. 


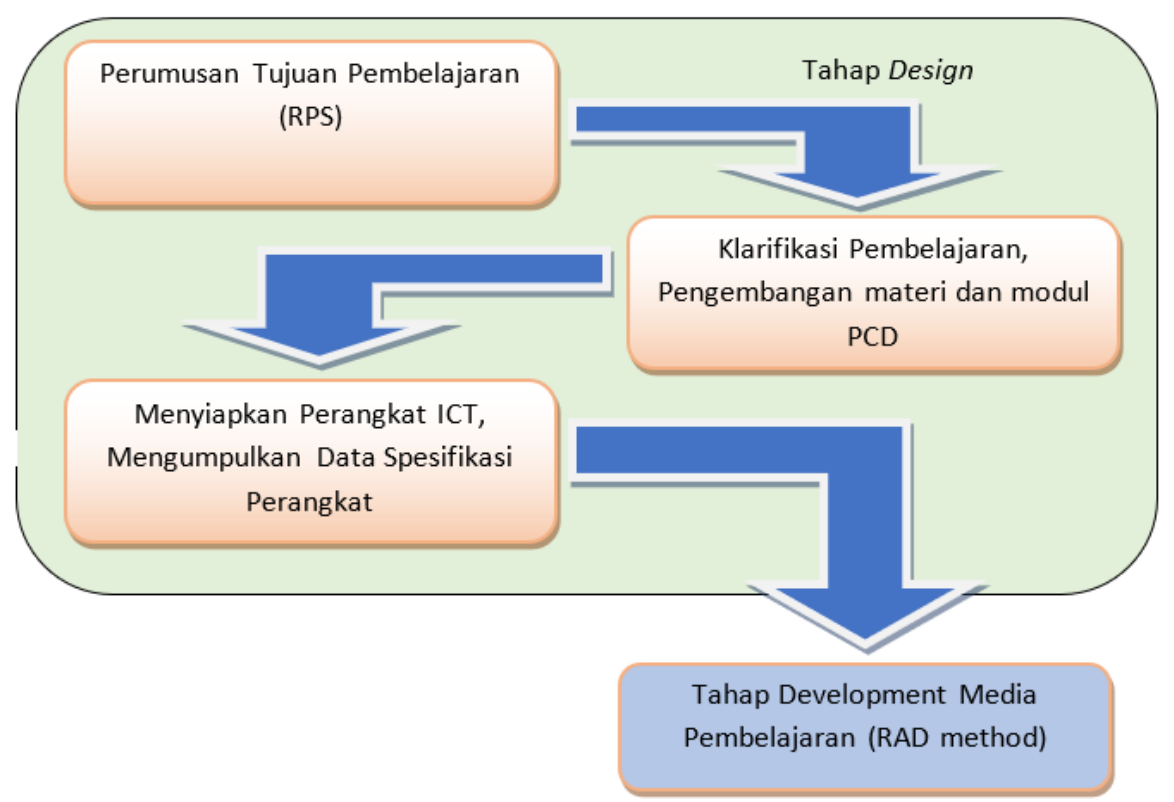

Gambar 1. Metode Penelitian DnD tahap Desain

Gambar 1 menunjukkan metode $\mathrm{DnD}$ di tahap desain. Perencanaan kebutuhan media harus disesuaikan dengan tujuan pembelajaran maka dari itu perlu desain pembelajaran yang tepat agar media sesuai dengan pembelajaran. Dimulai dengan perumusan tujuan yakni berupa penyesuain materi dengan RPS supaya topik dan materi yang disampaikan sesuai dengan tujuan pembelajaran. Tahap klarifikasi pembelajaran yakni pengembangan materi berupa cetak dimana nantinya akan dimuat dalam aplikasi mobile yakni tentang materi pengolahan citra digital dan modul praktikum yang digunakan mahasiswa dalam proses pembelajaran berbasis proyek. Aktifitas terakhir di tahap desain adalah menentukan spesifikasi perangkat yang dapat mendukung penggunaan media pembelajaran. Hal ini sangat diperlukan agar media pembelajaran dapat diakses diberbagai perangkat mobile dan tidak terjadi eror.

Agar perangkat pembelajaran siap untuk dikembangkan ke media digital perlu diberikan penilaian oleh ahli media, berikut kisi-kisi penilaian perangkat ajar.

Tabel 1. Lembar Penilaian Validasi Media

\begin{tabular}{|c|c|c|c|}
\hline No. & $\begin{array}{c}\text { Aspek yang } \\
\text { dinilai }\end{array}$ & Indikator & $\begin{array}{l}\text { Skor } \\
(1-4)\end{array}$ \\
\hline 1. & \multirow{5}{*}{$\begin{array}{l}\text { Rencana } \\
\text { Pembelajaran }\end{array}$} & Kesesuaian model & \\
\hline 2. & & Tata Bahasa & \\
\hline 3. & & Prosedur pembelajaran & \\
\hline 4. & & Evaluasi pembelajaran & \\
\hline 5. & & Referensi yang digunakan & \\
\hline 6. & \multirow{6}{*}{$\begin{array}{l}\text { Materi / modul } \\
\text { ajar }\end{array}$} & Kesesuaian tujuan & \\
\hline 7. & & Kesukaran materi & \\
\hline 8. & & Kelengkapan materi & \\
\hline 9. & & Tata bahasa & \\
\hline 10 & & Kesesuaian hasil praktik dengan materi & \\
\hline 11 & & Sistematika penyajian materi & \\
\hline
\end{tabular}

Perangkat pembelajaran siap dikembangkan ke aplikasi jika mencapai angka 3 atau lebih. Maka setelah tahap desain telah disetujui untuk dikembangkan maka dilanjutkan tahap development. Tahap pengembangan ini sudah masuk dalam pengembangan media pembelajaran berbasis android dengan menggunakan metode $\mathrm{RAD}$, berikut skematik tahap developmen menggunakan RAD. 


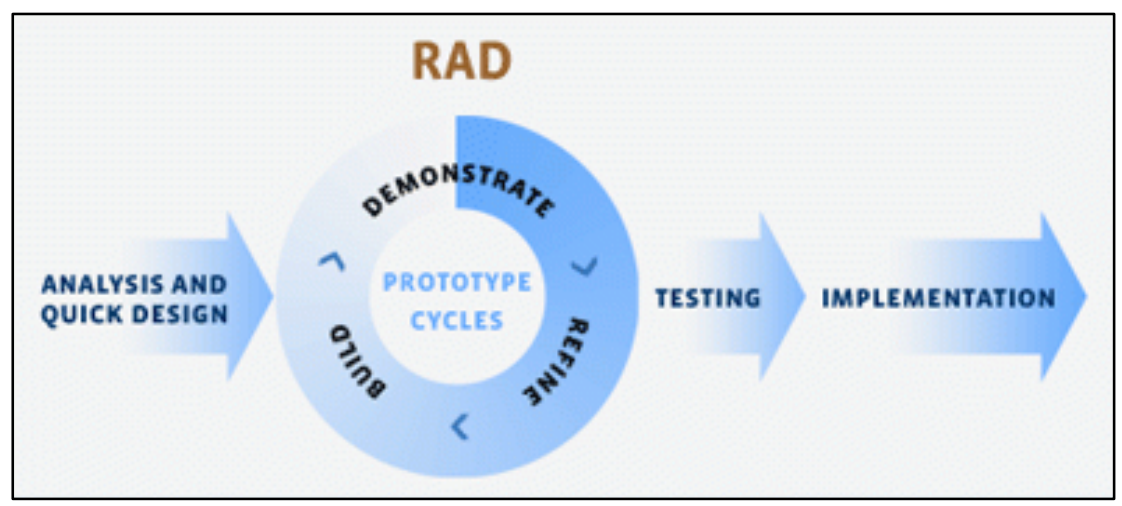

Gambar 2. Metode Rapid Application Development

Metode RAD pertama kali diawali dengan analysis and quick design dimana analisis konten dan desain kebutuhan telah dilaksanakan ditahap desain $\mathrm{DnD}$ maka masuk dalam prototype cyrcles dimana setiap bagian aplikasi atau materi yang telah dikembangkan langsung diujicobakan untuk mengetahui kesalahan atau hal yang perlu ditambahkan. Sebenarnya RAD ini digunakan untuk pengerjaan proyek pengembangan aplikasi dalam jangka waktu pendek, sehingga bertujuan untuk mengefisiensi waktu pengembangan aplikasi. Jika semua bagian aplikasi dan materi dianggap sesuai dengan tujuan dan proses pembelajaran maka masuk di tahap testing dimana akan diujicobakan di intern peneliti yang dimana bertujuan untuk dikonsultasikan ke ahli media tentang kesesuaian media terhadap RPS. Jika dianggap sudah sesuai baru diimplementasikan di kelas sample dimana digunakan untuk menilai media pembelajaran yang dikembangkan.

Dari fungsionalitasnya, aplikasi atau modul digital ini digunakan oleh dosen atau pengajar sebagai pembuat konten materi dan mahasiswa sebagai pengguna aplikasi dalam proses pembelajaran. Dengan media ini diharapkan dapat memudahkan dosen dalam memberikan materi pembelajaran secara digital. Proses pembelajaran dan penggunaan aplikasi dapat ditunjukkan pada gambar Unified Modeling Language (UML) berikut ini.

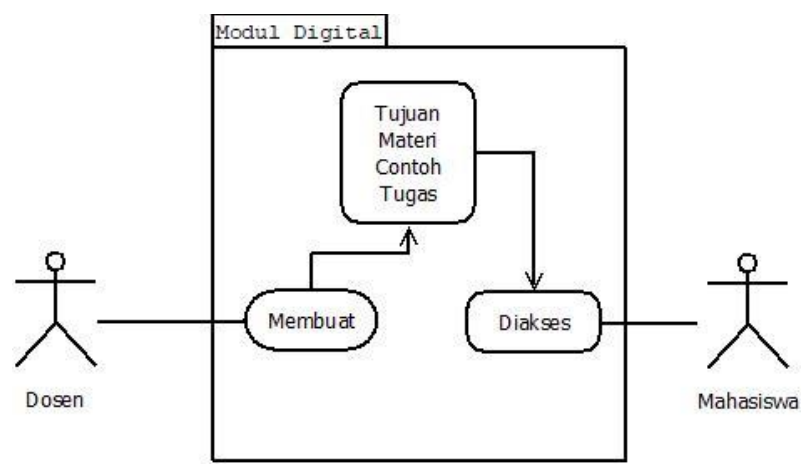

Gambar 3. Metode Rapid Application Development

Modul digital yang telah dibuat akan diujikan kepada mahasiswa sebagai pengguna media ini. Hasil dari pengujian akan dianalisis menggunakan pengukuran distribusi normal. Distribusi normal atau kurva normal (Distribusi Gausse) adalah suatu alat statistic yang penting untuk menaksir dan meramalkan peristiwaperistiwa yang lebih luas. Suatu data membentuk distribusi normal bila jumlah data di atas dan di bawah mean adalah sama. [7]

Bentuk kurva normal menyerupai bentuk bel. Kurva normal adalah simetris, sehingga luas rata-rata (mean) ke kanan dan ke kiri masing-masing 50\%. Memiliki satu modus, jadi kurva unimodal. Ruangan yang dibatasi daerah kurva dengan absisnya disebut daerah kurva normal. 


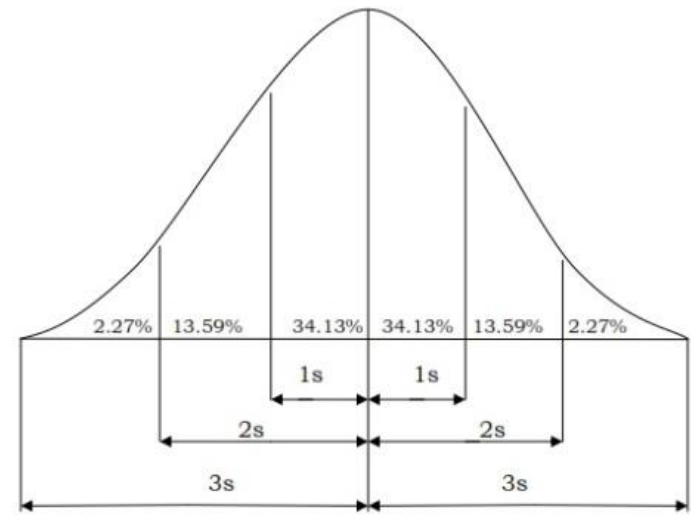

Gambar 4. Daerah Kurva Normal

Luas daerah kurva normal biasa dinyatakan dalam persen atau proporsi. Dengan kata lain luas daerah kurva normal adalah serratus persen, apabila dinyatakan dalam persen, dan apabila dinyatakan dengan proporsi, luas daerah kurva normal adalah satu. Kurva normal standar atau kurva normal baku adalah kurva normal yang mana nilai rata-ratanya sama dengan nol dan simpangan bakunya adalah 1 (0). Dalam kurva normal umum nilai rata-rata sama dengan x dan nilai simpangan baku $1 \mathrm{~s}, 2 \mathrm{~s}$, 3s dengan kata lain dalam kurva normal nilai rata-ratanya tidak sama dengan nol dan nilai simpangan bakunya tidak sama dengan 1(1). Kurva normal umum dapat diubah kedalam kurva normal baku dengan menggunakan rumus:

$$
\mathbf{z}=\frac{x-\bar{x}}{s}
$$

Dimana : $\mathrm{z}=$ nilai standard; $\mathrm{x}=$ data ke-i dari suatu kelompok data; $\bar{x}=$ rata-rata kelompok $; \mathrm{s}=$ simpangan baku

\section{Hasil dan Pembahasan}

Tahap pengisian angket oleh mahasiswa telah dilaksanakan. Modul yang dibuat terdapat 9 materi pemrograman yang berisi tentang tujuan, petunjuk, dasar teori, latihan dan tugas.

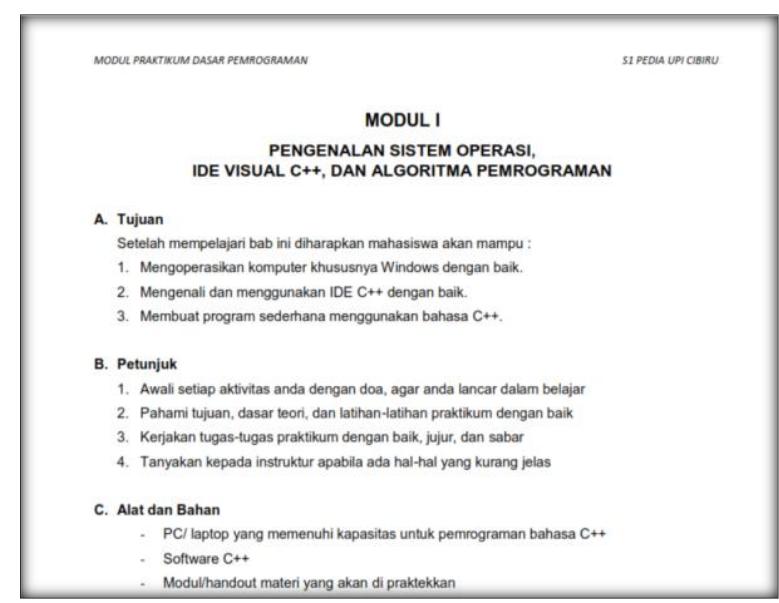

Gambar 5. Contoh modul yang telah dibuat

Modul digunakan sebagai sumber materi untuk membuat konten dalam media. Media dibuat dengan google site. Dengan fitur-fitur yang memudahkan pengajar untuk memngembangkan media, google site sangat cocok digunakan. Salah satu keunggulan menggunakan google site adalah semua aplikasi atau layanan yang disediakan google dapat terhubung langsung. Sehingga dapat dikembangkan berbagai macam media dalam satau layanan aplikasi ini. 


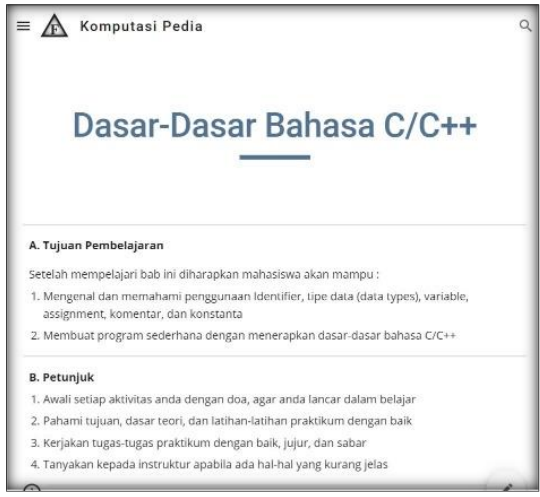

Gambar 6. Tampilan modul pembelajaran via desktop

Media ini dapat diakses dengan berbagai macam perangkat dan dengan dukungan interface yang menyesuaikan dengan ukuran layer perangkat sangat memudahkan mahasiswa untuk belajar dimana saja.

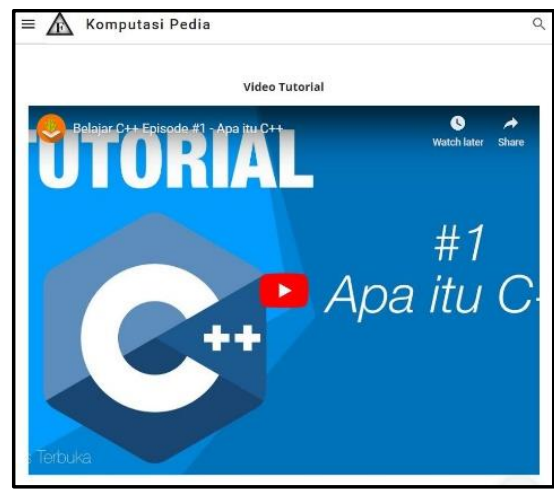

Gambar 7. Video pembelajaran yang ada di dalam modul

Dengan didukung berbagai layanan google, media ini sangat cocok dengan berbagai jenis media yang dapat ditampilkan dalam satu halaman.

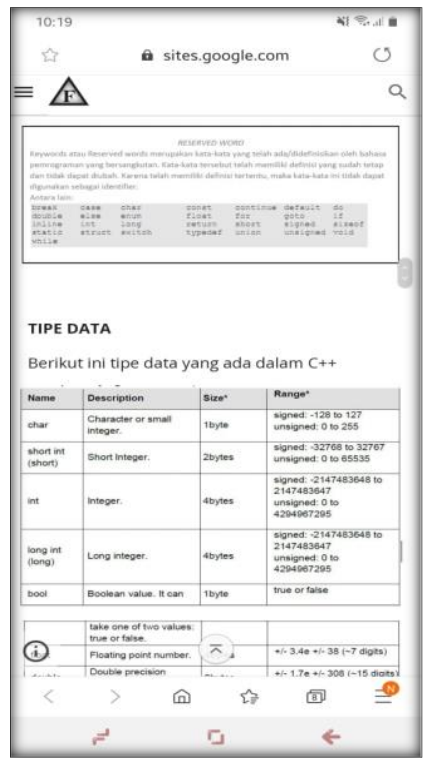

Gambar 8. Modul praktik dibuka melalui smartphone

Modul yang dibuat mengacu kepada tujuan pembelajaran yang bersumber dari RPS mata kuliah algoritma struktur data. Pada tahap pengumpulan data telah didapatkan data mentah yang belum diolah lewat pengisian angket oleh mahasiswa. Adapun hasil angket yang didapatkan ditunjukkan di gambar 7. Setelah semua perangkat telah dibuat yakni RPS, modul pembelajaran dan site google kemudia kegiatan penelitian dilanjutkan dengan melaksanakan pengisian angket respon oleh pengguna aplikasi pembelajaran yakni 
mahasiswa Pendidikan Multimedia. Jumlah responsa da 57 mahasiswa yang ditunjukkan pada gambar 8 berikut.

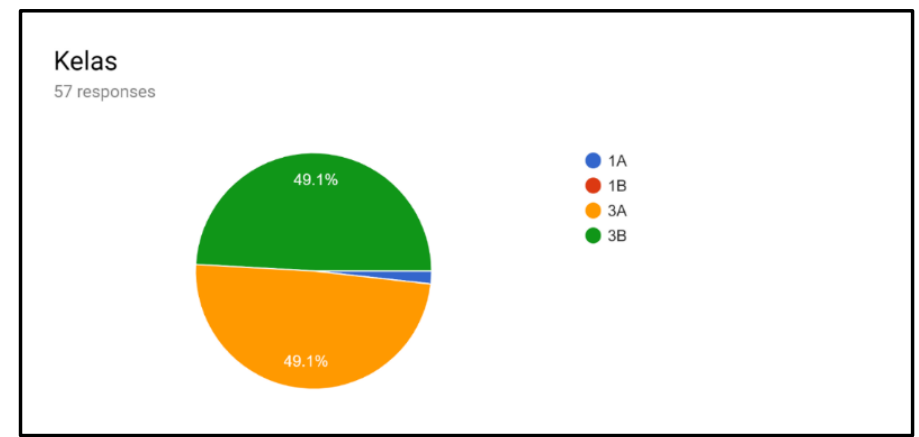

Gambar 9. Jumlah responden mahasiswa yang mengisi angket

Dalam pengisian angket ini mahasiswa diinstruksinkan untuk mengakses media secara online dengan menggunakan komputer dan gawai dari masing-masing mahasiswa. Tidak ditentukan spesifik berapa jumlah pengguna komputer dan gawai, yang terpenting adalah mereka dapat mengakses modul dan melakukan praktik sesuai dengan instruksi yang ada dalam modul tersebut. Karena pengisian angket dilaksanakan di luar jadwal perkuliahan sehingga pemakaian media tidak pada kelas formal, melainkan sebatas penggunaan media sebagai alat bantu belajar. Dalam penilaian media, peneliti menentukan 3 hal penilaian terkait penggunaan media yakni dari aspek pemrograman, aspek konten, dan aspek tampilan.

Pada penilaian aspek pemrograman didapatkan hasil sebagai berikut.

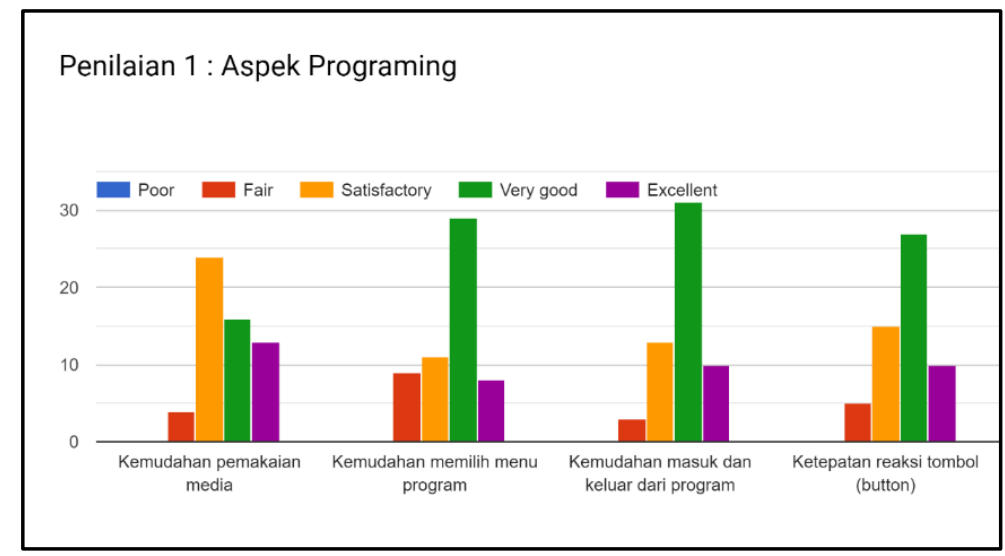

Gambar 10. hasil pengisian angket 1

Di gambar 9 terdapat 5 tingkat penilaian jika menggunakan rentang 0-100 maka poor=20, fair=40, satisfactory $=60$, verygood $=80$ dan excellent $=100$. Karena kurva normal memiliki rentang dari minus satu $(-1)$, nol(0), satu (1) maka nilai 100 ini adalah acuan letak kurva rentang 1. Dari data di atas didapatkan hasil sebagai berikut.

Tabel 2. Hasil Angket Pemrograman

\begin{tabular}{cc}
\hline Poor & 0 \\
\hline Fair & 21 \\
\hline Satisfactory & 64 \\
\hline Very Good & 103 \\
\hline Excellent & 40 \\
\hline
\end{tabular}

Dari tabel 2 dapat dihitung menggunakan kurva normal, pertama menentukan standar aplikasi dengan mentukan nilai $\mathrm{x}=60$ dan rata-rata yang didapatkan dari data di tabel 1 adalah $\mathrm{x}$ rata-rata $=74.21$ dan didapatkan simpangan baku (s) adalah 17.21. Sehingga jika dimasukkan rumusnya maka: 


$$
\begin{gathered}
z=\frac{x-\bar{x}}{s} \\
z=\frac{60-74.21}{17.21} \\
Z=-0.82
\end{gathered}
$$

Dari perhitungan tersebut jika ditarik kedalam kurva normal maka 1+z atau 1-0.82 didapatkan hasil 0.18.

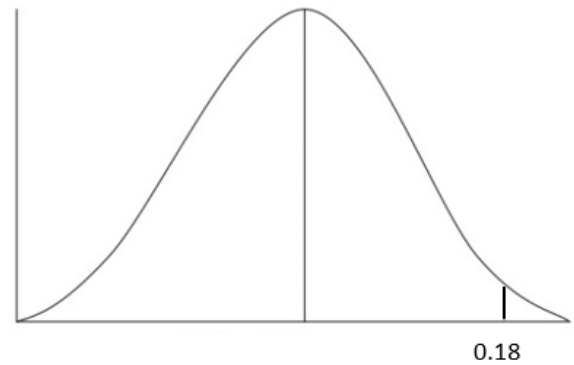

Gambar 11. kurva normal aspek pemrogaraman

Gambar 11 menunjukkan penilaian dari segi pemrograman menjorok ke kanan pada 0.18 dimana menunjukkan bahwa kelayakan media dari pemrogramannya sangat baik (ditunjukkan dengan nilai 0.18 kurang dari nilai simpangan baku (3s) ke kanan).

Selanjutnya penilaian dari segi konten didapatkan hasil sebagai berikut.

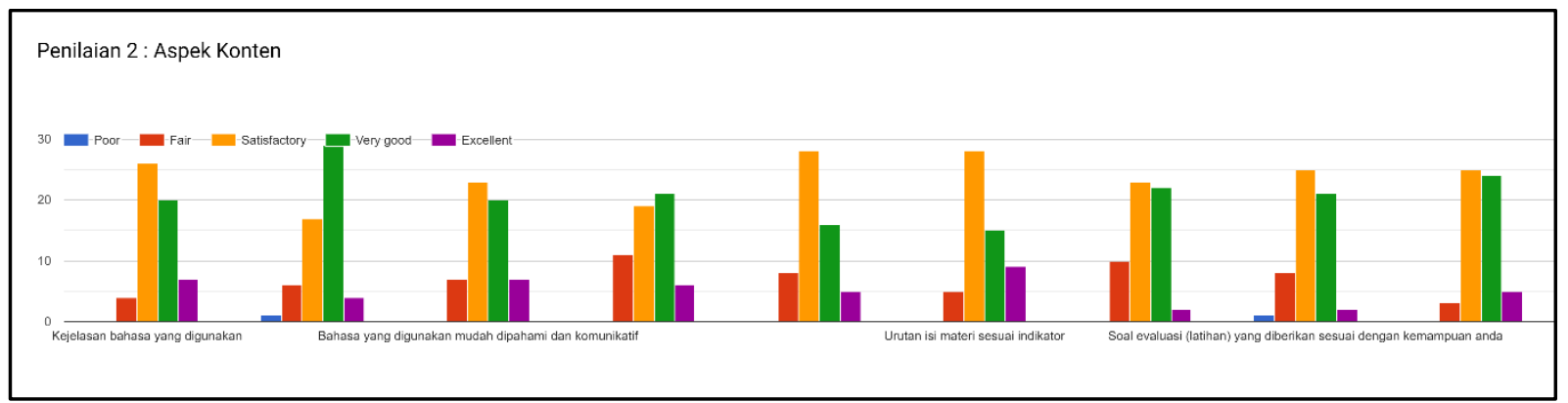

Gambar 12. hasil pengisian angket 2

Rentang penilaian yang digunakan sama dengan penilaian sebelumnya sehingga didapatkan hasil sebagai berikut.

Tabel 3. Hasil Angket Aspek Konten

\begin{tabular}{cc}
\hline Poor & 2 \\
\hline Fair & 62 \\
\hline Satisfactory & 214 \\
\hline Very Good & 188 \\
\hline Excellent & 47
\end{tabular}

Dari tabel 3 didapatkan nilai simpangan baku 16.64 dan rata-rata $\mathrm{x}=68.42$ sehingga jika dihitung menggunakan rummus sebagai berikut.

$$
\begin{gathered}
z=\frac{x-\bar{x}}{s} \\
z=\frac{60-68.42}{16.64} \\
z=-0.506
\end{gathered}
$$


Rentang 0-1 pada kurnva normal dengan menggunakan perhitungan di atas didapatkan nilai 1-0.506 sama dengan 0.49 . Hasil ditunjukkan pada gambar 12 berikut ini.

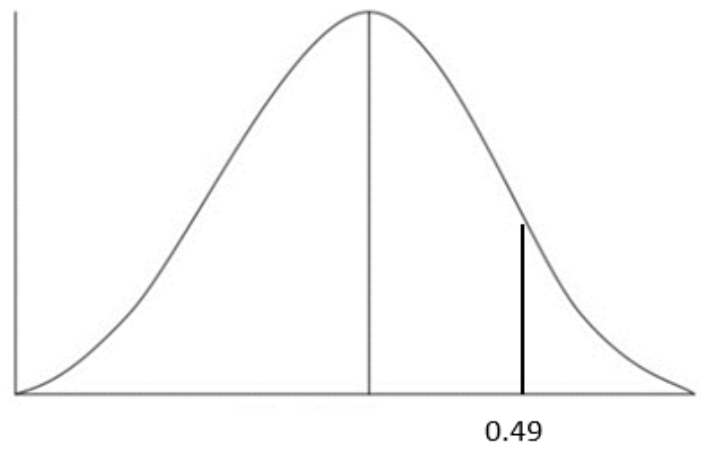

Gambar 13. kurva normal aspek konten

Dari gambar di atas menunjukkan hasil penilaian dari segi konten menjorok ke kanan pada nilai 0.49. Hal ini menunjukkan konten yang digunakan dalam media sangat sesuai jika digunakan dalam proses perkuliahan karena sesuai dengan hasil perhitungan.

Perhitungan ketiga adalah dari segi tampilan aplikasi menggunakan google site ini. Didapatkan hasil pengisian angket sebagai berikut.

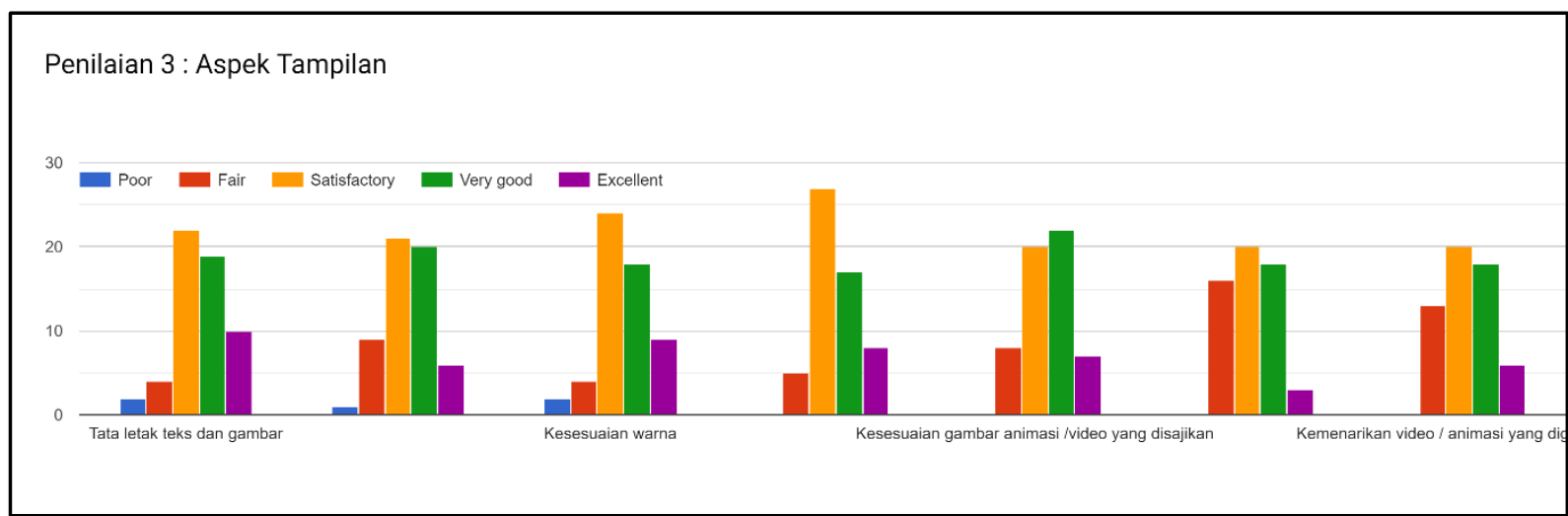

Gambar 14. hasil pengisian angket 3

Dari gambar 13 didapatkan hasil sebagai berikut.

Tabel 4. Hasil Angket Aspek Tampilan Aplikasi

\begin{tabular}{cc}
\hline Poor & 5 \\
\hline Fair & 59 \\
\hline Satisfactory & 154 \\
\hline Very Good & 132 \\
\hline Excellent & 49 \\
\hline
\end{tabular}

Dari tabel 3 didpatkan nilai simbangan baku sebesar 18.52 , rata-rata $\mathrm{x}=68.07$. Sehingga nilai $\mathrm{z}$ yang didapatkan sebagai berikut.

$$
\begin{gathered}
z=\frac{x-\bar{x}}{s} \\
Z=\frac{60-68.07}{18.52} \\
Z=-0.436
\end{gathered}
$$


Nilai z yang didapat sebesar -0.436 sehingga nilai yang ditunjukkan di kurva adalah 1-0.436 sama dengan 0.56 .

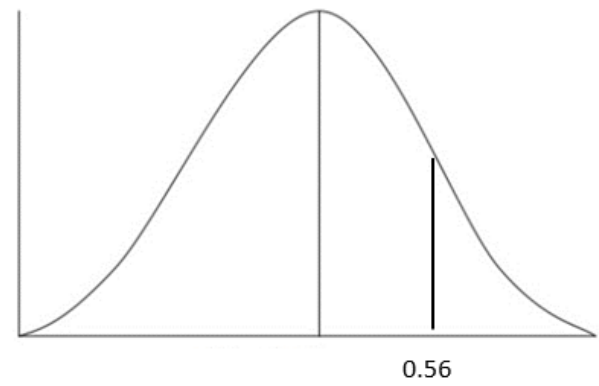

Gambar 15. kurva normal aspek tampilan aplikasi

Kurva menunjukkan hasil posotif dengan nilai 0.56 menjorok ke kanan. Tampilan program atau modul online ini cukup menarik bagi pengguna.

\section{Simpulan}

Modul pembelajaran yang telah dikembangkan dapat diakses secara digital dan online melalui berbagai jenis perangkat baik komputer maupun gawai. Untuk pengembangan media menggunakan gawai, modul didukung aplikasi berbasis android yang dapat diakses oleh mahasiswa secara online melalui aplikasi ini. Karena berbasis online maka aplikasi ini tidak dapat digunakan secara offline kecuali discreenshoot terlebih dahulu tiap halaman dari modul digital. Dari hasil pengukuran angket yang didapatkan, media pembelajaran menggunakan google site dan berbasis android ini ditunjukkan dengan hasil aspek usability atau pemrogramannya sesuai dengan kebutuhan pemakai atau user di sini adalah mahasiswa. Konten yang dimuat dalam modul digital juga sangat membantu mahasiswa dalam proses pembelajaran dan tampilan atau interface dari aplikasi ini cukup menarik sehingga tidak membuat mahasiswa merasa bosan untuk belajar menggunakan modul digital ini. Aplikasi ini akan digunakan sebagai salah satu media dalam pembelajaran jarak jauh pada penelitian selanjutnya.

\section{Daftar Pustaka}

1. Ahmad, Intan. 2018. Proses Pembelajaran Digital dalam Era Revolusi Industri 4.0. Medan. Ristekdikti.

2. Tosepu, Yusrin. Tantangan di Era Revolusi Industri 4.0 dan Implementasi Kebijakan Pembelajaran Berbasis Penelitian di Perguruan Tinggi. Makasar: LSP3I. Accessed on: academia.edu

3. Tosepu, Yusrin. Digitalisasi Pendidikan: Telaah Dunia Pendidikan menuju Transformasi Digital. Makasar : LSP3I. Accessed om : academia.edu.

4. Arsyad, Azhar. 2014. Media Pembelajaran. Jakarta: PT Rajagrafindo Persada.

5. Dale, E. 1969. Audiovisual methods in teaching (3rd edition). New York. Dryden Press.

6. O’Malley, C. 2003. Guidelines for learning/Teaching/Tutoring in Mobile Environment.

7. Suharyadi, dan S. K. Purwanto,2009, Statistika: Untuk Ekonomi dan Keuangan Modern, Edisi 2, Buku 1, Penerbit Salemba Empat, Jakarta. Halaman 25-39.

8. Candra Permana, Fahmi dkk.. 2019. Rancang Bangun Aplikasi Pendeteksi Jenis Golongan Darah Berdasarkan Konsep Kepercayaan Rakyat Jepang (Minkan Shinkō). Jurnal Pendidikan Multimedia vol 1 No 1. Halaman 25-34

\section{Ucapan Terima Kasih}

Terima kasih kepada Universitas Pendidikan Indonesia yang telah mendanai penelitian ini lewat kegiatan Hibah Dana Penelitian LPPM tahun 2019. 